\title{
ChemComm
}

\section{A novel P450-based biocatalyst for the selective production of chiral 2-alkanols $\dagger$}

Cite this: Chem. Commun., 2014, 50,4089

Received 24th January 2014

Accepted 24th February 2014

DOI: $10.1039 / c 4 c c 00647 j$

www.rsc.org/chemcomm

\author{
Clemens J. von Bühler and Vlada B. Urlacher*
}

\begin{abstract}
A P450 monooxygenase from Nocardia farcinica (CYP154A8) catalyses the stereo- and regioselective hydroxylation of $n$-alkanes, still a challenging task in chemical catalysis. In a biphasic reaction system, the regioselectivity for the $\mathrm{C} 2$-position of $\mathrm{C}_{7}-\mathrm{C}_{9}$ alkanes was over $90 \%$. The enzyme showed strict $S$-selectivity for all tested substrates, with enantiomeric excess (ee) of up to $91 \%$.
\end{abstract}

Chiral linear alcohols are widely used as building blocks in the synthesis of pharmaceuticals, agrochemicals, pheromones and liquid crystals and therefore synthetic routes to these products are of high interest. ${ }^{1}$ Besides the difficult and less selective chemical routes, ${ }^{2}$ the enzymatic reduction of prochiral ketones catalysed by alcohol dehydrogenases is an established enzymatic process for the production of chiral alcohols. ${ }^{3}$ However, a prerequisite for this enzymatic approach is the availability of functionalised substrates, namely ketones. Therefore, an enzymatic approach for the production of chiral secondary alcohols via direct hydroxylation of inert alkanes by a monooxygenase seems to be more beneficial. Alkanes are cheap starting compounds that are easily produced from mineral oil and hence are available in high amounts. Enzyme-catalysed selective hydroxylation of alkanes comes along with the typical advantages of biocatalytic processes: no requirement for toxic metal catalysts or high reaction temperatures and only limited use of potentially toxic additional organic solvents.

Several enzyme groups have been described that are capable of this type of reaction. ${ }^{4}$ The number of oxygenases producing secondary and particularly 2 -alcohols is however limited. The soluble methane monooxygenase (SMMO) and the particulate methane monooxygenase (pMMO) from Methylococcus capsulatus produce 2-alcohols from short chain alkanes but suffer from low expression. ${ }^{5}$ Furthermore fungal peroxygenases accept small and medium chain alkanes as substrates but display moderate regioselectivity. ${ }^{6}$

Institute of Biochemistry, Heinrich-Heine University Düsseldorf, Universitätsstraße 1, 40225 Düsseldorf, Germany. E-mail: Vlada.Urlacher@uni-duesseldorf.de;

Fax: +492118113117; Tel: +492118113866

$\dagger$ Electronic supplementary information (ESI) available: Materials and methods. GC/MS chromatograms, time dependence of octane conversion, and supplementation experiments. See DOI: 10.1039/c4cc00647j
A very large and intensively studied group of enzymes catalysing hydroxylation reactions are the heme containing cytochrome $\mathrm{P} 450$ monooxygenases (P450s). Several wild type and engineered P450s are known to accept alkanes as substrates and especially CYP102A enzymes are known to produce 2-alcohols. ${ }^{7}$

Recently, we characterised two novel P450 enzymes belonging to the CYP154 family. ${ }^{8}$ CYP154A8 from Nocardia farcinica IFM 10152 proved to be quite regioselective. Thus, this enzyme was chosen for a detailed investigation of its suitability as a biocatalyst for $n$-alkane oxidation.

CYP154A8 was expressed in $E$. coli in soluble form and purified as reported earlier. ${ }^{8}$ A catalytically active P450 system was then reconstituted by the addition of the flavodoxin YkuN from Bacillus subtilis and E. coli flavodoxin reductase $\mathrm{FdR} .{ }^{8}$ Reactions were performed in $500 \mu \mathrm{l}$ reaction volume under $\mathrm{NADPH}$ cofactor regeneration by glucose dehydrogenase. The following alkanes were tested as substrates: heptane $\left(\mathrm{C}_{7}\right)$, octane $\left(\mathrm{C}_{8}\right)$, nonane $\left(\mathrm{C}_{9}\right)$, decane $\left(\mathrm{C}_{10}\right)$ and dodecane $\left(\mathrm{C}_{12}\right)$. After extraction and derivatisation, the reaction mixtures were analysed via achiral and chiral GC coupled with MS. The stereoselectivity of the enzyme was chain length dependent. In comparison to authentic standards it could be determined that CYP154A8 showed strict $S$-selectivity for all tested alkanes: $84 \%$ ee for both 2-(S)-heptanol and 2-(S)-nonanol, 63\% ee for 2 -(S)-decanol and a maximum of $91 \%$ ee was found for 2-(S)-octanol (Fig. S1, ESI $\dagger$ ). Dodecane was accepted by CYP154A8 but only trace amounts of products were formed and hence this alkane was not investigated further. In the case of decane oxidation, $27 \%$ 3-decanol was formed with $89 \%$ ee.

By monitoring the octane conversion over a period of $24 \mathrm{~h}$ it could be demonstrated that the ee value of the formed 2-(S)-octanol was not dependent on the degree of conversion, as is expected for an asymmetric synthesis (Fig. S2, ESI $\dagger$ ).

So far the best-characterised P450s that catalyse this reaction with high stereoselectivity are the CYP102A1 mutants F87V/A328F ${ }^{9} 1-12 \mathrm{G}^{10}$ and $139-3,{ }^{10,11}$ which all produce 2-octanol, but with significantly lower ee-values, i.e. $46 \%$ ee for $2-(R)$-octanol, $39 \%$ ee for $2-(R)$-octanol and $58 \%$ ee for $2-(S)$-octanol, respectively. Thus CYP154A8 is the first P450 enzyme that is 


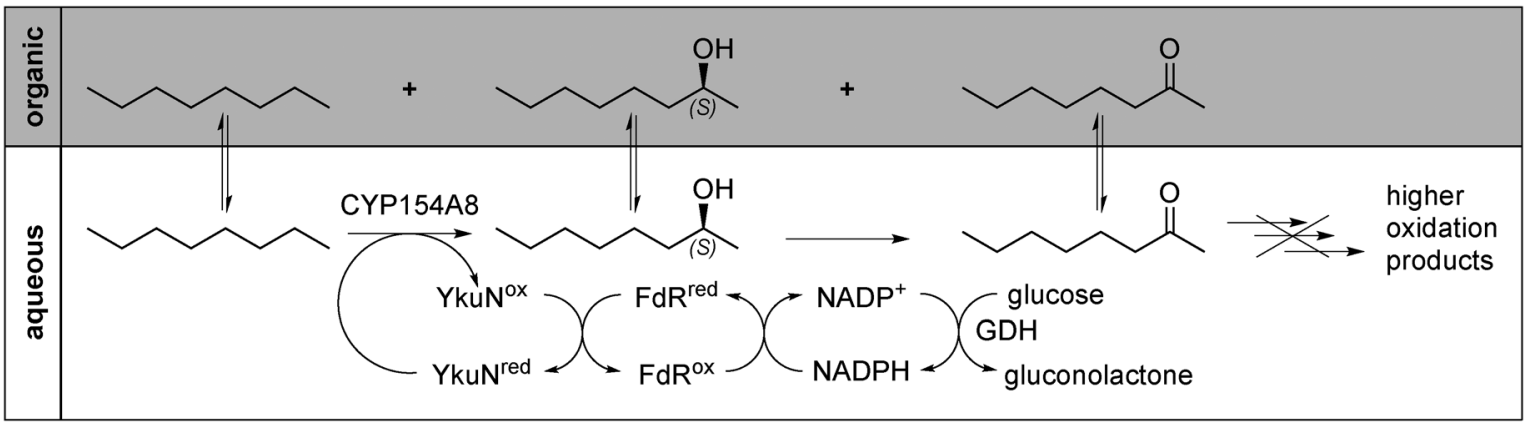

Scheme 1 Hydroxylation of octane catalysed by CYP154A8 in a biphasic reaction system consisting of an organic substrate phase and an aqueous phase. The product scavenging effect of the organic phase prevents formation of higher oxidation products. YkuN (flavodoxin from B. subtilis), FdR (E. coli flavodoxin reductase), GDH (glucose dehydrogenase from B. megaterium).

shown to produce highly enantiomerically enriched 2-(S)-octanol from octane.

However, substrate conversion in aqueous solution resulted in the formation of higher oxidation products, diols, which are produced upon exposure of the formed 2-alcohol to the enzyme as described earlier. ${ }^{8}$ In order to circumvent the formation of the undesired products, the reaction setup was modified: by employing the substrate as a second phase ( $20 \mathrm{vol} \%$ of the aqueous phase) a double benefit over the homogenous aqueous reaction system was achieved. First, the concentration of the substrate available to the enzyme was maximised, and second, the continuous extraction of formed products into the organic phase minimised or even prohibited the formation of higher oxidation products (Scheme 1). Partition coefficients for all 2-alcohols have been determined in the respective biphasic alkane-buffer-systems. Values ranged between $\log P_{\mathrm{C} 7} 1.0 \pm 0.03$ for 2-heptanol and $\log P_{\mathrm{C} 10} 1.42 \pm 0.1$ (Table S1 and Section S4.4, ESI $\dagger$ ). This altered reaction setup yielded 2 -alcohols as main reaction products with over $80 \%$ selectivity. Considering that some of the 2-alcohol molecules were obviously further oxidised by CYP154A8 to the corresponding ketones, an overall preference towards the C2-position of up to $90 \%$ can be calculated (Fig. 1A-C and Fig. S3, ESI $\dagger$ ).

Similar to the stereoselectivity, the regioselectivity of CYP154A8 was chain length dependent and decreases for $\mathrm{C}_{10}$ down to $70 \%$ (Fig. 1D and Fig. S3, ESI $\dagger$ ). For decane a significant amount of 3-decanol as well as its overoxidation product 3-decanone was detected. GC/MS data confirmed that 3-alkanones were not present for any other substrate but decane.

The benchmark for our reaction was the data published by Peters et al. (2003) for the CYP102A1 mutant 1-12G, ${ }^{11}$ and data for the CYP102A1 mutant F87V/A328F designed in our group. ${ }^{9}$ The mutant enzyme 1-12G produces 2-alcohols from alkanes ranging from $\mathrm{C}_{7}-\mathrm{C}_{10}$ with a corresponding selectivity of $76,82,86$, and $86 \%$. However, in all cases alcohols with a hydroxy group at the positions C1, C3 and C4 were observed as by-products. Compared to 1-12G, CYP154A8 showed a higher or similar regioselectivity depending on the chain length of the substrate, but its product distribution was limited to the C2- and partially C3-position only. The mutant F87V/A328F is very selective for the C2-position of octane (92\%). ${ }^{9}$ Thus, the total regioselectivity of CYP154A8 for the C2-position was comparable to that of F87V/A328F.
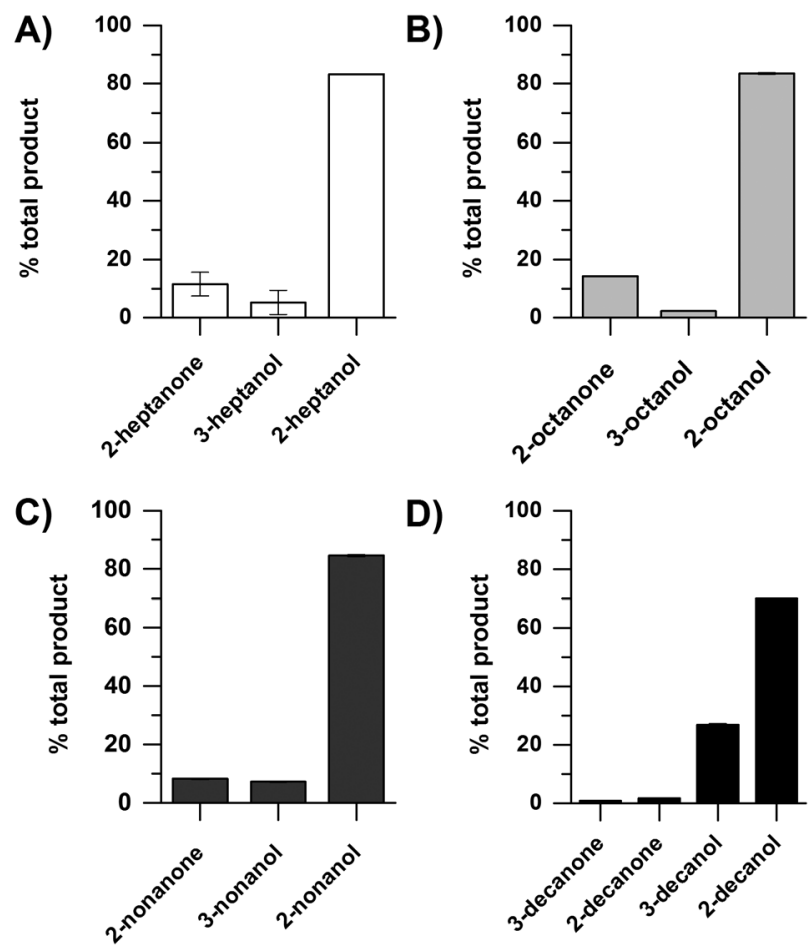

Fig. 1 Product distribution after hydroxylation of various alkanes: (A) heptane, (B) octane, (C) nonane, and (D) decane, determined from GC/MS peak areas and plotted as percentage of a specific product to the total amount of product (Fig. S3, ESI $\dagger$ ). Where error bars cannot be seen, they are smaller than the linewidth.

In the next step challenges inherent to biphasic reaction systems such as interfacial surface area, low substrate solubility in the aqueous phase, and the choice of protein stabilising additives have been addressed. The optimised biphasic system included catalase to decompose $\mathrm{H}_{2} \mathrm{O}_{2}$, which might be formed by a shunt reaction in the catalytic cycle of $\mathrm{P} 450 \mathrm{~s},{ }^{12}$ BSA for protein stabilisation, ${ }^{13}$ ethanol as a cosolvent and the use of a rotator for mixing (Section S8 and Fig. S4, ESI $\dagger$ ).

The following product titres were obtained after $24 \mathrm{~h}$ in the optimised biphasic reaction system: $3 \mathrm{mM}$ 2-nonanol; $1.9 \mathrm{mM}$ 2-heptanol; 2.2 mM 2-octanol; and 1.2 mM 2-decanol. Compared to values found for CYP102A1 mediated octane hydroxylation ${ }^{9,11}$ 
Table 1 Parameters for the 2-hydroxylation of heptane, octane, nonane and decane catalysed by CYP154A8

\begin{tabular}{llrlll}
\hline Sub. & $\begin{array}{l}\text { Product } \\
\text { formation rate }\end{array}$ & \multicolumn{1}{c}{$\begin{array}{l}\text { Coupling }^{b} \\
(\%)\end{array}$} & $\begin{array}{l}\text { Conc. }^{c} \\
(\mathrm{mM})\end{array}$ & TTN $^{c, d}$ & $\begin{array}{l}\text { ee- }(S)^{c} \\
(\%)\end{array}$ \\
\hline $\mathrm{C}_{7}$ & $1.13 \pm 0.08$ & $7.3 \pm 0.9$ & 1.9 & 2800 & 84 \\
$\mathrm{C}_{8}$ & $4.6 \pm 1.04$ & $21.1 \pm 4.2$ & 2.2 & 3200 & 91 \\
$\mathrm{C}_{9}$ & $3.73 \pm 0.44$ & $15.9 \pm 1.8$ & 3.0 & 4400 & 84 \\
$\mathrm{C}_{10}$ & $0.37 \pm 0.05$ & $4.0 \pm 0.6$ & 1.2 & 1700 & 63
\end{tabular}

${ }^{a}$ Given as nmol of 2 -alcohol per nmol $\mathrm{P} 450$ per minute. ${ }^{b}$ Determined using a $200 \mu \mathrm{l}$ aqueous reaction system in multiwell plates with $1 \mathrm{mM}$ substrate. ${ }^{c}$ After $24 \mathrm{~h}$ in $500 \mu \mathrm{l}$ of a biphasic reaction system. ${ }^{d}$ Calculated as nmol of 2-alcohol per nmol P450.

the total turnover numbers (TTNs) of CYP154A8 were much higher than those reported for $\mathrm{F} 87 \mathrm{~V} / \mathrm{A} 328 \mathrm{~F}$ and in the same order of magnitude as those of $1-12 \mathrm{G}$ (Table 1). Moreover, these results demonstrated that even though the catalytic system consisted of five enzymes, this complexity apparently does not have a negative effect on product formation.

In P450 systems at various stages of the electron transfer chain, electrons can be diverted from a productive reaction, leading to unproductive cofactor consumption, which reduces the catalytic performance of the system. This can take place between redox partners as well as through the earlier mentioned shunt reactions in the P450 catalytic cycle. To evaluate the performance of the CYP154A8 system we calculated the coupling between NADPH consumption and product formation (Table 1 and ESI $\dagger$ ). The rather low values (Table 1) are however in accordance with those reported for other artificial P450 redox chains oxidising non-natural substrates. ${ }^{14}$

At a closer look these data seem to be contradictory: the total turnover number (TTN) and the final product concentration were highest for nonane but its product formation rate and coupling were lower than for octane.

Since we attributed this discrepancy to the stability of the involved enzymes we designed experiments to verify our hypothesis: octane conversion was supplemented after $5.5 \mathrm{~h}$ with either additional glucose, glucose dehydrogenase (both for cofactor regeneration), YkuN/FdR or YkuN/FdR/P450. After a total reaction time of $24 \mathrm{~h}$ each case was compared to a standard reaction setup without this extra addition. Neither the addition of glucose nor that of glucose regenerating GDH resulted in an elevated final product concentration. As opposed to this, the supplementation of the reaction with the redox partners or the $\mathrm{P} 450$ led to about $15 \%$ more product which could even be further maximised $(45 \%)$ by the simultaneous addition of YkuN, FdR and CYP154A8 (Fig. S5, ESI $\dagger$ ). These results indicated that as suggested the stability of the redox partner proteins and that of CYP154A8 turned out to have a major influence on the degree of conversion. In the $\mathrm{C}_{7}$ to $\mathrm{C}_{12}$ alkane series the solubility decreases from $3.4 \mathrm{mg} \mathrm{L} \mathrm{L}^{-1}$ to $5.210^{-2} \mathrm{mg} \mathrm{L}{ }^{-1} \cdot{ }^{15}$ It is therefore reasonable to assume that enzyme denaturation is decreased with a longer alkane chain, due to reduced exposure.
This in turn may explain the observed higher final concentrations of 2-nonanol as compared to 2-octanol (Table 1).

In conclusion, CYP154A8 from $N$. farcinica was identified as a novel regio- and stereoselective biocatalyst for the hydroxylation of inert $n$-alkanes. Depending on the substrate chain length, enzyme preference for oxidation at the C2-position was more than $90 \%$. To the best of our knowledge, CYP154A8 is the only P450 monooxygenase where high regioselectivity for medium chain alkane hydroxylation coincides with a moderate to high enantiomeric excess of the formed 2-(S)-alcohols and high total turnover numbers. Furthermore, by means of reaction optimisation the total product amounts were significantly increased to levels that can compete with the best performing and well-established CYP102A1based systems. But unlike those evolved CYP102A1 systems, CYP154A8 wild type shows already high selectivity, which might be even further increased by protein engineering methods. Compared to other enzymes like fungal peroxygenases both regio- and stereoselectivity of 2-alkanol production by CYP154A8 is significantly higher. ${ }^{6}$ This study demonstrates the potential of CYP154A8 in alkane oxidation. Simultaneously, the described biocatalyst implies additional optimisations and the transfer to a whole cell system which are currently under investigation.

\section{Notes and references}

1 (a) K. Faber and M. C. Franssen, Trends Biotechnol., 1993, 11, 461; (b) N. Öhrner, C. Orrenius, A. Mattson, T. Norin and K. Hult, Enzyme Microb. Technol., 1996, 19, 328; (c) R. A. Sheldon, J. Chem. Technol. Biotechnol., 1996, 67, 1.

2 R. H. Crabtree, J. Chem. Soc., Dalton Trans., 2001, 2437.

3 W. Kroutil, H. Mang, K. Edegger and K. Faber, Curr. Opin. Chem. Biol., 2004, 8, 120.

4 (a) Y. Ji, G. Mao, Y. Wang and M. Bartlam, Front. Microbiol., 2013, 4, 58; (b) J. B. Van Beilen and E. G. Funhoff, Appl. Microbiol. Biotechnol., 2007, 74, 13; (c) M. Bordeaux, A. Galarneau and J. Drone, Angew. Chem., Int. Ed., 2012, 51, 10712.

5 (a) S. J. Elliott, M. Zhu, L. Tso, H.-H. T. Nguyen, J. H.-K. Yip and S. I. Chan, J. Am. Chem. Soc., 1997, 119, 9949; (b) S. I. Chan, K. H.-C. Chen, S. S.-F. Yu, C.-L. Chen and S. S.-J. Kuo, Biochemistry, 2004, 43, 4421.

6 S. Peter, M. Kinne, X. Wang, R. Ullrich, G. Kayser, J. T. Groves and M. Hofrichter, FEBS J., 2011, 278, 3667.

7 O. Lentz, V. Urlacher and R. D. Schmid, J. Biotechnol., 2004, 108, 41.

8 C. von Bühler, P. Le-Huu and V. B. Urlacher, ChemBioChem, 2013, 14, 2189.

9 E. Weber, A. Seifert, M. Antonovici, C. Geinitz, J. Pleiss and V. B. Urlacher, Chem. Commun., 2010, 46, 944.

10 A. Glieder, E. T. Farinas and F. H. Arnold, Nat. Biotechnol., 2002, 20, 1135. 11 M. W. Peters, P. Meinhold, A. Glieder and F. H. Arnold, J. Am. Chem. Soc., 2003, 125, 13442.

12 P. R. Ortiz de Montellano, Cytochrome P450. Structure, mechanism, and biochemistry, Kluwer Academic/Plenum Publishers, New York, 3rd edn, 2005.

13 S. C. Maurer, K. Kühnel, L. A. Kaysser, S. Eiben, R. D. Schmid and V. B. Urlacher, Adv. Synth. Catal., 2005, 347, 1090.

14 (a) A. Schallmey, G. den Besten, I. G. P. Teune, R. F. Kembaren and D. B. Janssen, Appl. Microbiol. Biotechnol., 2011, 89, 1475; (b) M. Girhard, T. Klaus, Y. Khatri, R. Bernhardt and V. B. Urlacher, Appl. Microbiol. Biotechnol., 2010, 87, 595; (c) S. G. Bell, C. F. Harford-Cross and L. L. Wong, Protein Eng., 2001, 14, 797.

15 National Library of Medicine (US), Division of Specialized Information Services, Hazardous Substances Data Bank, available at: http:// toxnet.nlm.nih.gov/cgi-bin/sis/htmlgen?HSDB. 